\title{
Viabilidade de células de levedura em massas congeladas de pão francês
}

\author{
Leavening cells viability in frozen French bread dough
}

\author{
Carolina Pereira Kechinski ${ }^{\mathrm{I}}$ Marcel Guigou Castro ${ }^{\mathrm{II}}$ Renata Jacob Fleck ${ }^{\mathrm{II}}$ \\ Caciano Zapata Noreña ${ }^{I I}$
}

RESUMO

A elaboração e o armazenamento de pães crus congelados têm se mostrado vantajosos para os pontos de venda e para o consumidor final. O primeiro, pela redução da perda e menor exigência de espaço físico e mão-de-obra especializada, e o segundo, por disponibilizar pães sempre frescos. O presente trabalho objetivou verificar a influência do armazenamento sobre a viabilidade das células de levedura em massas congeladas de pão francês. Para tanto, as massas foram elaboradas seguindo a metodologia de massa direta: os ingredientes (pré-mistura para pão francês, fermento fresco e água) foram misturados até o desenvolvimento completo do glúten; então foi dividida em porções de $60 \mathrm{~g}$ e modelada. $\mathrm{O}$ congelamento foi realizado em ultracongelador a $-32{ }^{\circ} \mathrm{C}$, e o armazenamento foi feito em câmaras com temperaturas de $18^{\circ} \mathrm{C} e-40^{\circ} \mathrm{C}$. Para a estimativa de vida de prateleira, analisouse a cinética da redução da viabilidade das leveduras. Esse teste foi realizado em placas de Petri contendo meio Sabouraud acrescido de cloranfenicol $0,2 \%$ a $28^{\circ} \mathrm{C}$ durante cinco dias. A cinética de redução das células de levedura seguiu uma reação de primeira ordem, cujas constantes de velocidades foram 0,027 dias $^{-1}\left(R^{2}=0,931\right)$ e 0,026 dias ${ }^{-1}\left(R^{2}=0,938\right)$ para as temperaturas de $-18^{\circ} \mathrm{C} e-40^{\circ} \mathrm{C}$, respectivamente. Para ambas as temperaturas, a redução em $50 \%$ da população de leveduras se deu em aproximadamente 25 dias.

Palavras-chave: panificação, leveduras, estabilidade.

\section{ABSTRACT}

The preparation and storage of frozen bread has proved to be advantageous for the market and to the final consumer. First because of loss reduction and need for smaller physical storage space and workforce, second because it provides always fresh bread. This study aimed to investigate the influence of storage on the viability of yeast cells in frozen French bread.
In order to that, frozen French breads were prepared by the direct-dough method: the ingredients (premix for French bread, fresh yeast and water) were mixed until the dough was fully developed and then divided into portions of $60 \mathrm{~g}$ and moulded. Freezing was held in ultra freezer at $-32^{\circ} \mathrm{C}$ and the storage was made in chambers at temperatures of $-18^{\circ} \mathrm{C}$ and $-40^{\circ} \mathrm{C}$. To estimate the shelf life, the study of reduction of leavening cells viability in frozen French bread dough was analyzed. This test was performed in Petri dishes containing Sabouraud agar with chloramphenicol $0.2 \%$ at $28^{\circ} \mathrm{C}$ during 5 days. The kinetics of reduction of leavening cells viability followed a first-order reaction, which rate constants were 0.027 days $^{-1}\left(R^{2}=0.931\right)$ and 0.026 day- ${ }^{1}\left(R^{2}=0.938\right)$ for $-18^{\circ} \mathrm{C}$ and $-40^{\circ} \mathrm{C}$ temperatures, respectively. For both temperatures, the $50 \%$ reduction in the number of leaven occurred in approximately 25 days.

Key words: panification, leaven, stability.

\section{INTRODUÇÃO}

O uso de massa congelada atende as exigências dos consumidores por pães sempre frescos, isto é, recém-assados. As vantagens do pão de massa congelada em relação aos processos tradicionais devem-se aos seguintes fatores: padronização do produto, redução de espaço e agilidade e flexibilidade para a produção. As padarias, assim, exercem apenas a função de pontos de venda do produto, onde os pães são descongelados, fermentados e assados, possibilitando a realização dessas operações em um espaço físico reduzido e dispensando a utilização de

IPrograma de Pós-graduação em Engenharia Química (PPGEQ), Departamento de Engenharia Química, Universidade Federal do Rio Grande do Sul (UFRGS), Rua Luis Englert, s/nº, Campus Central, 90040-000, Porto Alegre, RS, Brasil. E-mail: carolpk@enq.ufrgs.br. Autor para correspondência.

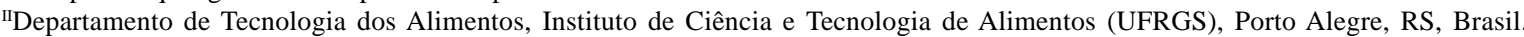


mão-de-obra especializada (SALAS-MELLADO, 2003; SALAS-MELLADO \& CHANG, 2003; GUTKOSKI et al., 2005).

As primeiras tentativas de produção de pão a partir de massa congelada ocorreram em 1926, na Áustria, com o uso de baixas temperaturas para o retardamento da etapa de fermentação da massa, numa tentativa de reduzir o trabalho noturno nas padarias. Na década de 50, algumas padarias de pequeno porte consideravam conveniente e econômico o congelamento de porções reserva de massa, que podiam ser mantidas por alguns dias ou semanas no congelador, para serem então descongeladas, fermentadas e assadas nos horários de maior demanda (GUTKOSKI et al., 2005).

A vida de prateleira ou shelf life de um alimento é definida como o tempo em que ele pode ser conservado em determinadas condições de temperatura, umidade relativa, luz e outras, sofrendo pequenas, mas bem estabelecidas alterações que são, até certo ponto, consideradas aceitáveis pelo fabricante, pelo consumidor e pela legislação vigente. Mesmo que um alimento esteja preservado e bem embalado, não será estável indefinidamente. Cada sistema se deteriora de forma diferente até que se atinja um ponto inaceitável, o qual não significa que esteja impróprio para consumo, mas que o padrão de qualidade pré-estabelecido não seja atingido, fazendo com que o tempo de fermentação seja muito longo. A fim de otimizar a vida de prateleira dos alimentos, o congelamento de produtos é atualmente uma das soluções mais viáveis economicamente como forma de conservação e logística de distribuição desses alimentos, entre os quais se inclui o pão francês.

O efeito do congelamento nas propriedades das leveduras tem sido um grande foco de estudo na tecnologia de panificação. Estudos têm mostrado que a viabilidade das leveduras é fortemente influenciada pelo tempo e pela temperatura da massa antes do congelamento (NEMETH et al., 1996). No caso de massas de pão destinadas para congelamento, é importante que a temperatura da massa antes do congelamento seja inferior a $20^{\circ} \mathrm{C}$, a fim de evitar que as leveduras iniciem o processo de fermentação antes do congelamento (GUTKOSKI et al., 2005).

A velocidade de congelamento deve ser suficientemente lenta para prevenir a formação de cristais no interior da célula e ao mesmo tempo rápida, para minimizar o tempo de exposição da célula aos efeitos da concentração da solução provocada pela cristalização da água. Recomenda-se que nenhuma parte da massa seja submetida a temperaturas inferiores a $-35^{\circ} \mathrm{C}$ para evitar danos excessivos às células de leveduras presentes na massa (CAUVAIN \& YOUNG, 2009). Diferentes autores mostraram que o congelamento rápido reduziu a capacidade de produção de gás e o número de células viáveis (INOUE et al., 1995; HAVET et al., 2000; RIBOTTA \& TADINI, 2009).

Portanto, a produção de pães congelados mostra-se vantajosa, mas necessita de um controle rígido da temperatura de congelamento e armazenamento, pois podem ocorrer alterações na atividade das células do fermento biológico, bem como alterações de textura, volume e qualidade do produto final (YI \& KERR, 2009). Esse controle deve ser realizado em todas as etapas, desde a produção da massa de pão até o ponto de venda. Porém, as condições de armazenamento nos pontos de venda nem sempre são ideais, apresentando oscilações na temperatura de armazenamento e reduzindo a vida útil e a qualidade do pão. Em vista disso, o presente trabalho objetivou verificar a influência da temperatura e do tempo de armazenamento sobre a viabilidade das células de levedura em massas congeladas de pão francês.

\section{MATERIAL E MÉTODOS}

Formulação dos pães e processamento

Para a formulação dos pães, foi utilizada a pré-mistura pronta para pão congelado (composta por farinha de trigo tipo 1, ferro, ácido fólico, sal, ácido ascórbico, estearoil 2-lactil lactato de sódio, azodecarbonamida, alfa-amilase, amiloglucosidase, fosfolipase, glúten e hemicelulase), fermento biológico fresco e água gelada a $4^{\circ} \mathrm{C}$, nas proporções indicadas na tabela 1. O processamento das massas congeladas de pão francês seguiu o fluxograma da figura 1, utilizando o método direto no qual todos os ingredientes foram adicionados na mesma etapa (CAUVAIN \& YOUNG, 2009) e misturados em amassadeira espiral (A-160, Progresso ${ }^{\circledR}$, Curitiba/PR, Brasil) até se obter uma massa suave e com o glúten bem desenvolvido. A massa foi então transferida para uma divisora/modeladora (GA-500, Progresso ${ }^{\circledR}$, Curitiba/PR, Brasil) regulada para frações de 60g de

Tabela 1 - Formulação base do pão francês.

\begin{tabular}{lll}
\hline Ingredientes & $\begin{array}{c}\text { Quantidade } \\
(\mathrm{kg})\end{array}$ & Porcentagem \\
\hline Pré-mistura para pão congelado & 100 & $100,0 \%$ \\
Água & 50 & $50,0 \%$ \\
Fermento biológico fresco & 5 & $5,0 \%$ \\
\hline
\end{tabular}




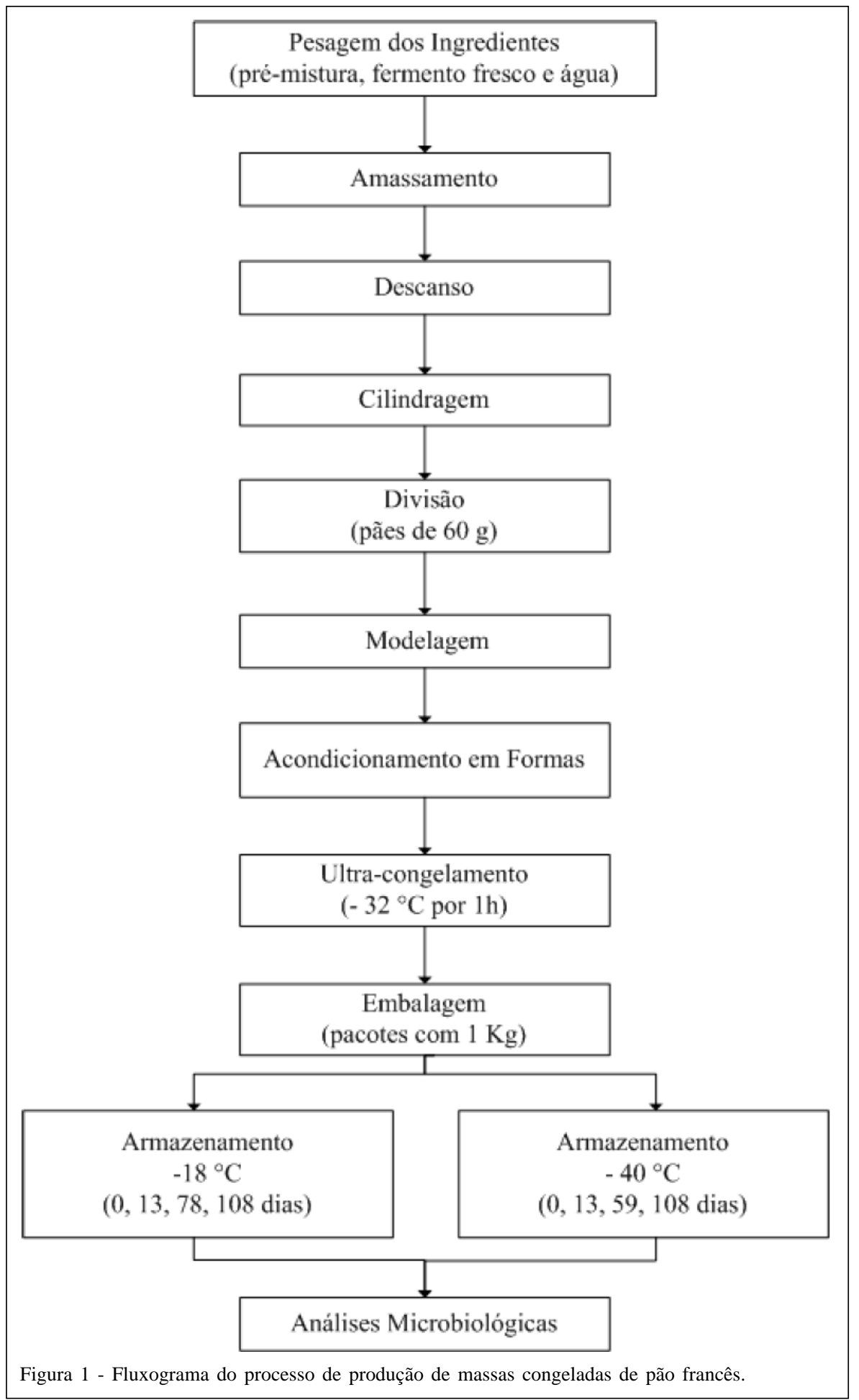

massa crua, o que resultará em pães assados com cerca de 50g. Os pães foram dispostos em bandejas plásticas, congelados em túnel de congelamento (TCB3, Rima Engenharia $^{\circledR}$, Porto Alegre/RS, Brasil) regulado a $-32^{\circ} \mathrm{C}$, durante uma hora, e armazenadas a duas diferentes temperaturas: $-18^{\circ} \mathrm{C}$ (Câmara de congelamento - Rima Engenharia ${ }^{\circledR}$ ) e a $-40^{\circ} \mathrm{C}\left(\right.$ em ultrafreezer - Terroni $\left.^{\circledR}\right)$. As análises foram realizadas após $0,13,18,59,108$ dias, para as amostras armazenadas a $-18^{\circ} \mathrm{C}$, e $0,13,18,59$, 108 dias, para as amostras armazenadas a $-40^{\circ} \mathrm{C}$. 
Análises microbiológicas

O preparo das amostras foi realizado em capela com fluxo laminar horizontal, previamente esterilizada. Para as análises microbiológicas, $25 \mathrm{~g}$ da massa de pão congelada foram homogeneizados em frascos de erlemeyer contendo $225 \mathrm{~mL}$ de água peptonada $0,1 \%$ e, na sequência, foram feitas diluições decimais até $10^{-6}$ (DOWNES, 2001).

As diluições foram inoculadas por espalhamento em placas de petri contendo meio Sabouraud e cloranfenicol na concentração de $200 \mathrm{mg} \mathrm{l}^{-1}$ (Cloranfenicol ${ }^{\circledR}$, Ducto, São Paulo, Brasil). As placas foram incubadas em estufas, a $28^{\circ} \mathrm{C}$, pelo período de cinco dias. Após esse período, realizou-se a contagem das placas, e o valor foi calculado sobre o peso da amostra de pão.

Cinética da redução da viabilidade de células de levedura

A perda de qualidade, para a maior parte dos alimentos, pode ser representada pela equação 1 (LABUZA, 1982; CARDELLI \& LABUZA, 2001; MANDALA et al., 2009):

$-\frac{d C}{d t}=K C^{n} \longrightarrow$ Equação (1)

em que: $C$ é o quantidade da variável em questão; t é a variável tempo; $K$ é a constante de velocidade da reação; $n$ é a ordem de reação que define se a taxa de perda é dependente ou não da quantidade de $C$ presente.

Para $\mathrm{n}=0$ (ordem zero), as reações têm uma taxa constante de perda de qualidade para uma dada temperatura e atividade de água (PHIMOLSIRIPOL et al., 2008) e, substituindo o valor de n na equação 1, é obtida a equação 2:

$-\frac{d C}{d t}=K \longrightarrow$ Equação

Integrando a equação 2 com as condições contorno, $\mathrm{t}=\mathrm{t} \mathrm{C}=\mathrm{C}$ e para $\mathrm{t}=0 \mathrm{C}=\mathrm{C}_{\mathrm{o}}$, tem-se a equação 3 , e a solução dessa integral está na equação 4 :

$\int_{C o}^{C} d C=-\int_{0}^{t} K d t \longrightarrow$ Equação (3)

$C=C_{o}-K t \longrightarrow$ Equação (4)

Para n=1 (reação de primeira ordem), partiuse também da equação 1 e das mesmas condições de contorno, chegando-se na equação 5. A resolução dessa integral pode ser observada nas Equações 6 e 7.

$\int_{C o}^{C} \frac{d C}{C}=-\int_{0}^{t} K d t \longrightarrow$ Equação

$\ln \left(\frac{C}{C_{o}}\right)=-K t \longrightarrow$ Equação

$\ln C=\ln C_{o}-K t \longrightarrow$ Equação
A reação com $n=2$ ( $2^{\mathrm{a}}$ ordem) partiu também da equação 1 e das mesmas condições de contorno, chegando-se na equação 8 . A resolução dessa integral pode ser observada nas equações 9 e 10.

$$
\begin{aligned}
& -\frac{d C}{d t}=K C^{2} \longrightarrow \text { Equação } \\
& \int_{C o}^{C} \frac{d C}{C^{2}}=-\int_{0}^{t} K d t \longrightarrow \text { Equação } \\
& \frac{1}{C}=\frac{1}{C_{0}}+K t \longrightarrow \text { Equação }
\end{aligned}
$$

\section{RESULTADOS E DISCUSSÃO}

Para determinação da vida de prateleira da massa congelada de pão francês, foi avaliado o comportamento do número de leveduras viáveis (C) nas duas temperaturas $\left(-18^{\circ} \mathrm{C} \mathrm{e}-40^{\circ} \mathrm{C}\right)$, para três ordens de reação (0, 1 e 2). A utilização de cloranfenicol se justifica, pois este, quando incorporado a meios de cultura a concentrações de 10 a $100 \mathrm{mg} \mathrm{L}^{-1}$, apresenta uma atividade antimicrobiana contra uma vasta gama de bactérias, que possam ter contaminado o meio de cultura (INOUE et al., 1995). Por meio de análises de regressão linear dos dados obtidos nas análises microbiológicas, foram obtidos os parâmetros das equações do modelo e $\mathrm{R}^{2}$, os quais são mostrados na tabela 2. Por meio dessa tabela, pode-se observar que o modelo que melhor representou o fenômeno de diminuição do número de leveduras viáveis foi o modelo da reação de ordem 1 . A diminuição do número de leveduras viáveis está relacionado com o tempo de armazenamento maior, causando danos às leveduras (BENASSI \& WATANABE, 2000). Por esse motivo, em massas congeladas, utiliza-se uma quantidade maior de levedura, pois parte delas será destruída durante o congelamento (GIANNOU et al., 2005; PHIMOLSIRIPOL, 2009).

A tabela 3 mostra o percentual de células viáveis ao longo do tempo de armazenamento nas

Tabela 2 - Constantes $\mathrm{k}$ e $\mathrm{R}^{2}$ para as regressões lineares das ordens de reação 0,1 e 2 .

\begin{tabular}{ccll}
\hline Ordem da Reação & Constante & $-18^{\circ} \mathrm{C}$ & $-40^{\circ} \mathrm{C}$ \\
\hline \multirow{2}{*}{0} & $\mathrm{~K}$ & $5,00 \mathrm{E}+06$ & $4,00 \mathrm{E}+06$ \\
& $\mathrm{R}^{2}$ & 0,730 & 0,865 \\
& & & \\
\multirow{2}{*}{1} & $\mathrm{~K}$ & $2,70 \mathrm{E}-02$ & $2,60 \mathrm{E}-02$ \\
& $\mathrm{R}^{2}$ & 0,931 & 0,938 \\
& & & \\
2 & $\mathrm{~K}$ & $2,70 \mathrm{E}-02$ & $2,60 \mathrm{E}-02$ \\
& $\mathrm{R}^{2}$ & 0,743 & 0,988 \\
\hline
\end{tabular}


Tabela 3 - Percentual de células viáveis ao longo do tempo de armazenamento nas temperaturas de $-18^{\circ} \mathrm{C}$ e $-40^{\circ} \mathrm{C}$.

\begin{tabular}{cccc}
\hline \multicolumn{4}{c}{ Temperatura de Armazenamento } \\
\hline \% células viáveis & $\mathrm{t}$ (dias) & \% células viáveis & $\mathrm{t}$ (dias) \\
$100 \%$ & 0 & $100 \%$ & 0 \\
$90 \%$ & 4 & $90 \%$ & 4 \\
$80 \%$ & 8 & $80 \%$ & 9 \\
$70 \%$ & 13 & $70 \%$ & 14 \\
$60 \%$ & 19 & $60 \%$ & 20 \\
$50 \%$ & 26 & $50 \%$ & 27 \\
$40 \%$ & 34 & $40 \%$ & 35 \\
$30 \%$ & 45 & $30 \%$ & 46 \\
$20 \%$ & 60 & $20 \%$ & 62 \\
$10 \%$ & 85 & $10 \%$ & 89 \\
$5 \%$ & 111 & $5 \%$ & 115 \\
$1 \%$ & 171 & $1 \%$ & 177 \\
\hline
\end{tabular}

temperaturas de $-18^{\circ} \mathrm{C} \mathrm{e}-40^{\circ} \mathrm{C}$. A partir dessa tabela, pode-se observar que, para ambas as temperaturas, a diminuição do número de células de leveduras viáveis ocorreu de maneira muito semelhante.

Cada produto possui uma temperatura própria de armazenamento, porém comercialmente costuma-se armazenar a $-18^{\circ} \mathrm{C}$, temperatura que está abaixo da transição vítrea (MATUDA) de massas fermentadas (CAUVAIN \& YOUNG, 2009). Os valores de Tg para massas são estimados em temperaturas inferiores a $-30^{\circ} \mathrm{C}$ (LAAKSONEN e ROOS, 2000; RIBOTTA et al., 2001), entre -30 e $-20^{\circ} \mathrm{C}$ (MATUDA, 2008), e superiores a $-20^{\circ} \mathrm{C}$ (CAUVAIN \& YOUNG 2009). Mesmo a $-20^{\circ} \mathrm{C}$, a massa congelada necessita de acondicionamento em sacos de polietileno ou de outro material que impeça a perda de água. Existem vários estudos descritos na literatura sobre o armazenamento de massas congeladas para pães que relatam a perda de qualidade do produto final, como o volume, por exemplo, que diminui ao longo do tempo de armazenamento em razão da perda de resistência à extensão da massa e do aumento do tempo de fermentação (RIBOTTA et al., 2001).

Comercialmente observa-se que, com uma redução de 50\% de células de levedura viáveis, os pães não apresentam o mesmo desempenho de fermentação. Em vista disso, conforme os dados observados na tabela 2, o tempo para armazenamento desses produtos em ambas as temperaturas é de aproximadamente 25 dias. Esse resultado vai ao encontro com o observado por BOT (2003), que verificou a diminuição do conteúdo de água não congelável no glúten em aproximadamente $1 \%$, nas três primeiras semanas de armazenamento congelado a $-15^{\circ} \mathrm{C}$. Além disso, resultados similares foram encontrados por SALASMELLADO \& CHANG (2003), que, em 45 dias a $-15^{\circ} \mathrm{C}$, observaram uma redução da viabilidade de leveduras de 53 a 99\%, variando de acordo com a formulação e o tipo de levedura.

\section{CONCLUSÃO}

Por meio do presente estudo, foi possível verificar que a temperatura e o tempo de armazenamento exercem influência sobre a viabilidade das células de levedura em massas congeladas de pão francês.

A equação da diminuição do número de células de leveduras viáveis no congelamento foi de primeira ordem, e as constantes de velocidade foram determinadas. Para ambas as temperaturas de armazenamento, a redução em $50 \%$ da população de leveduras se deu aos 25 dias, aproximadamente.

\section{REFERÊNCIAS}

BENASSI, V.T.; WATANABE, E. O uso de massa congelada na produção de pão. Boletim do Centro de Pesquisa e Processamento de Alimentos, v.18, n.1, p.71-84, 2000.

BOT, A. Differential scanning calorimetric study on the effects of frozen storage on gluten and dough. Cereal Chemistry, v.80, n.4, p.366-370, 2003. Disponível em: <www.aaccnet.org/ cerealchemistry/articles/2003/0614-01R.pdf $>$. Acesso em: 08 mar. 2010. Publication nํㅡ-2003-0614-01R.

CARDELLI, C.; LABUZA, T.P. Application of Weibull hazard analysis to the determination of the shelf-life of roasted ground coffee. LWT-Food Science and Technology, v.34, n.5, p.273278, 2001. Disponível em: <http://www.sciencedirect.com/ s c i e n c e / a r t i c le / B 6 W M V- 458 N M 0 V - $10 / 2$ / bf46c3e8bc0cfda2c5ab86c18f976d0e>. Acesso em: 08 mar. 2010. doi: 10.1006/fstl.2000.0732.

CAUVAIN, S.P.; YOUNG, L.S. Tecnologia de panificação. Barueri: Manole. 2009. 440p.

DOWNES, F.P.; ITO, K. Compendium of methods for the microbiological examination of foods. Washington: American Public Health Association. 2001. 676p.

GIANNOU, V. et al. Quality and safety of frozen bakery products. In: SUN, D.W. (Ed). Handbook of frozen food processing and packaging. New York: Marcel Dekker, 2005. p.487-490.

GUTKOSKI, L.C. et al. Efeito de ingredientes na qualidade da massa de pão de forma congelada não fermentada durante o armazenamento. Ciência e Tecnologia de Alimentos, v.25, p.460-467, 2005. Disponível em: <www.scielo.br/pdf/cta/ v25n3/27012.pdf>. Acesso em: 08 mar. 2010. doi: 10.1590/ S0101-20612005000300012.

HAVET, M. et al. Influence of the freezing condition on the baking performances of French frozen dough. Journal of Food Engineering, v.45, n.3, p 139-145, 2000. Disponível em: 
$<$ http://www.sciencedirect.com/science/article/B6T8J-405KDXJ3/2/5092ed081e4f6641873ce8a2676fa96d>. Acesso em: $08 \mathrm{mar}$. 2010. doi: 10.1016/S0260-8774(00)00050-9.

INOUE, Y. et al. Studies on frozen doughs. IV. Effect of shortening systems on baking and rheological properties. Cereal Chemistry, v.72, p.221-224, 1995. Disponível em: <http://www.aaccnet.org/cerealchemistry/backissues/1995/ 72_221.pdf $>$. Acesso em: 08 mar. 2010.

LAAKSONEN, T.J.; ROOS, Y.H. Thermal, dynamic-mechanical, and dielectric analysis of phase and state transitions offrozen wheat doughs. Journal of Cereal Science, v.32, n.3, p.281-292, 2000. Disponível em: <http://www.sciencedirect.com/science/article/ B6WHK-45FC8XH-7/2/6bad02823e455539d31e35f42875de09>. Acesso em: 08 mar. 2010. doi: 10.1006/jcrs.2000.0338.

LABUZA, T.P. Shelf-life dating of foods. Westport: Food \& Nutrition, 1982. 500p.

MANDALA, I. et al. Influence of frozen storage on bread enriched with different ingredients. Journal of Food Engineering, v.92, n.2, p.137-145, 2009. Disponível em: <http://www.sciencedirect.com/science/article/B6T8J-4SVKSJ23/2/eecf554acc99006f4b7c493bd2bc2fb8>. Acesso em: 08 mar. 2010. doi: 10.1016/j.jfoodeng.2008.06.020.

MATUDA, T. Estudo do congelamento da massa de pão: determinação experimental das propriedades termofísicas e desempenho de panificação. São Paulo: Escola Politécnica, Universidade de São Paulo, 2008. 153p.

NEMETH, L.J. et al. Effects of ingredients and processing conditions on the frozen dough bread quality of a Canada Western Red Spring wheat flour during prolonged storage. Food Research International, v.29, n.7, p.609-616, 1996. Disponível em: $<$ http://www.sciencedirect.com/science/article/B6T6V3W3FG74-4/2/64a56206c18bc49042407f36afe665d1>. Acesso em: 08 mar. 2010. doi: 10.1016/S0963-9969(96)00070-1.

PHIMOLSIRIPOL, Y. et al. Effects of freezing and temperature fluctuations during frozen storage on frozen dough and bread quality. Journal of Food Engineering, v.84, n.1, p.48-56, 2008. Disponível em: <http://www.sciencedirect.com/science/article/
B6T8J-4NKJ07G-6/2/4f26f3331c422a3e3cc217551c547a6b>. Acesso em: 08 mar. 2010. doi: 10.1016/j.jfoodeng.2007.04.016.

PHIMOLSIRIPOL, Y. Shelf life determination of frozen bread dough stored under fluctuating temperature conditions. Kasetsart Journal (Natural Science), v.43, p.187-197, 2009. Disponível em: <http://kasetsartjournal.ku.ac.th/ kuj_files/2009/ A0902161449232165.pdf >. Acesso em: 08 mar. 2010.

RIBOTTA, P.D. et al. Effect of freezing and frozen storage of doughs on bread quality. Journal of Agricultural and Food Chemistry, v.49, n.2, p.913-918, 2001. Disponível em: $<$ http://dx.doi.org/10.1021/jf000905w $>$. Acesso em: $08 \mathrm{mar}$. 2010. doi: 10.1021/jf000905w.

RIBOTTA, P.D.; TADINI, C.C. Alternativas tecnológicas para la elaboración y conservación de productos panificados. Córdoba: Cyted, 2009. 329 p. Disponível em: <http://digital.csic.es/ bitstream/10261/17843/1/libro\%20panificacion-2009.pdf>. Acesso em: 08 mar. 2010.

SALAS-MELLADO, M.M. Estudo da influência da formulação e das condições operacionais dos tipos de congelamento na qualidade da massa e do pão. 2003. 242f. Tese (Doutorado em Engenharia de Alimentos) - Faculdade de Engenharia de Alimentos, Universidade Estadual de Campinas, Campinas, SP.

SALAS-MELLADO, M.M.; CHANG Y.K. Effect of formulation on the quality of frozen bread dough. Brazilian Archives of Biology and Technology, v.46, p.461-468, 2003. Disponível em: <http:// www.scielo.br/scielo.php?script=sci_arttext\&pid=S151689132003000300018\&lng=en.>. Acesso em: 08 mar. 2010. doi: 10.1590/S1516-89132003000300018.

YI, J.; KERR, W.L. Combined effects of freezing rate, storage temperature and time on bread dough and baking properties. LWT - Food Science and Technology, v.42, n.9, p.14741483, 2009. Disponível em: <http://www.sciencedirect.com/ s c i ence / a r t i c le / B 6 W M V - 4 W C S R G R - 1 / 2 / 70d599e03f4c89ad1ebd20faaa9f0984>. Acesso em: 08 mar. 2010. doi: 10.1016/j.lwt.2009.05.017. 